\title{
Determinants Impacting Efficacy of Organizational Blogs
}

\author{
Rajesh Sharma \\ Research Scholar \\ Indian Institute of Management, Indore \\ Professor Kamal K. Jain \\ Indian Institute of Management, Indore
}

\begin{abstract}
Recent revolution in the Information and Communication Technology has brought forth several tools for organizational learning and knowledge transfer. Organizational blogging has received considerable attention for its use for managed socialization leading to dialogue, reflection and knowledge transfer among the employees of large organizations. However this powerful tool of knowledge sharing can lead to adverse consequences in the absence of suitable checks in organizations. The paper uses the framework of interpersonal relationships proposed by Hon and Grunig to identify determinants that can impact efficacy of organizational blogs as a knowledge sharing tool. A case study of organizational blog of a leading service provider of India in the field of communication is presented for validating the findings from the literature. We suggest the possibility of using moderator to overcome the anticipated pitfalls in use of this popular medium of knowledge sharing in organizations.
\end{abstract}

Keywords: Organizational blog, knowledge sharing, discussion board, managed socialization.

\section{INTRODUCTION}

The term Weblog (combination of word 'web' and 'log'), which was first used by Jorn Barger on his Robot Wisdom website in 1997 (Kaiser et al., 2007), got contracted with its frequent use and is now widely known as blog. It has gained increasing importance since the advent of Web 2.0 as a tool for disseminating knowledge internally among staff and externally among customers and suppliers (McAfee, 2009). Several variants of this common term have come in vogue in recent times like discussion boards, forums, message boards, bulletin boards, wikis and organizational blogs. Though these terms are used interchangeably due to similarity of purpose such as publishing thought, opinions and ideas on the web, collaboration within a group, and commenting on other people's contribution, there are subtle differences between them which are non-trivial. While discussion forums are topic centred, blogs are author centred and wikis are content/document centred (http://www.adelaide.edu.au/myuni/staff/resources/tutorials/content)

Organizational blog is generally regarded as an online tool which is initiated by an organization for knowledge sharing among its members. According to Kelleher \& Miller (2006), 'organizational blogs are Web logs that meet three criteria. They are maintained by people who post in an official or semi-official capacity at an organization, endorsed explicitly or implicitly by that organization, and posted by a person perceived by public to be clearly affiliated with the Organization'. The topics in this group are more focused on the specific business unit and not on the general information which the employees would engage in. The majority of these 
blog topics focus on the organization and the functional activities defined by being part of that group (Stephens, 2013). The membership of the organizational blogs is in most cases limited to its members and it is hosted on the intranet of the organization with access control.

The types of organizational blogs can be further categorized either on the basis of the user group or the purpose of the blog. Some of the examples of organizational blogs are employee blogs, group blogs, executive blogs, promotional blogs and newsletter blogs (Lee et al., 2008).The discussions in these blogs are organised into topics by 'threads' and can be initiated by anyone in the community on a topic of choice. All participants have an equal voice and they make use of technologies to facilitate communications and collaboration either in a corporate or personal environment (Carlin et.al. 2008, Hasan \& Pfaff, 2006).

Blogs are widely believed to be a very useful tool for knowledge sharing in an organization by promoting dialogue (Efimova and de Moor, 2005), supporting the process of reflections (Roll, 2004) and leading to formation of communities of practice (Silva et al., 2006) for collaboration and sharing of best practices (Ojala , 2004). However, in spite of these apparent advantages of blogs and their widespread use in recent times for creating knowledge-sharing environment, there have been instances in which the organizations have experienced negative effects of such an open communication channel in the organization (Bishop, 2003; Cone, 2005) and the organization had to fire employees for their acts of discretion.

Several empirical studies have been carried out to measure the usefulness and success of internal blogs in specific contexts in the organization such as Microsoft (Efimova \& Grudin, 2007) and IBM (Jina et al. 2007). However, there is a paucity of research in the reverse direction, i.e., there are not many studies to understand the organizational factors that have a positive impact on the use of blogs in the organizations for the purpose of organizational learning. The objective of this paper is to attempt to fill this research gap by identifying a set of factors which can have an impact on the efficacy of blogs as a tool of managed socialization in organizations.

\section{RESEARCH METHODOLOGY}

Since much research is not available for such kind of study, exploratory research methodology is used for the current study wherein a literature review is carried out to identify the existing frameworks for identifying the factors that impact the efficacy of organizational blogs. Based on the review, we put forth a set of propositions for efficacy of organizational blogs. In order to validate these propositions, we carried out a content analysis of the posts on the discussion forum of a leading service provider of India in the field of communication. Two time frames were chosen for the study - one (2009) when the organizational blog was running without any problem and the second (2011) just before it was decided to be closed by the management. The content analysis is carried out by going through the posts and replies on the blogs and categorizing them as either useful for knowledge sharing or otherwise. The analysis is validated by review by an expert faculty who was suitably briefed about the context of the study.

By such comparison in two periods where the organization environment was significantly altered, we seek to highlight how the changes in organizational environment can result in the negative changes in content of the discussion forum. In this way, the validity of our propositions for efficacy of discussion forum is triangulated. 


\section{LITERATURE REVIEW}

Blogs are defined in various ways in the literature starting from the original definition of Jorn Barger in 1997 as mentioned in the previous section. In general, a blog is essentially considered to be a diary of personal reflections- called as post- that is shared on the World Wide Web. Readers can react to the posts of the blogger, and these comments are attached to the main post for other readers to examine (Wattal, 2009). According to Baoill (2004), the format of a blog includes small chunks of content referred to as posts, date stamped, reverse chronological order, and content expanded to include links, text and images.

Therefore, it is essentially a chronological and interactive tool for communication and collaboration because the "conversational nature" of blogs allow members of that blog to share ideas and opinions about particular topics and subject matters of interest to them (Baxter \& Connolly, 2013)

Blogs are used as an important tool for organizational learning which, according to the interpretive view, "occurs through shared insights, knowledge, and mental models...builds on past knowledge and experience - that is, on memory" (Stata, 1989). This view of organizational learning is supported by Wenger (1991) who believes that learning in organisations must be perceived as being a social phenomenon because individuals are essentially social beings. Moitra and Kumar (2007) argue that the inability to capitalize on the tacit knowledge stems from a missing 'social' dimension in the design of knowledge management strategies, which when addressed leads to unleashing the valuable tacit knowledge. Drawing on real-world research spanning twelve leading companies, they discuss Managed Socialization-the most vital management process for harnessing global knowledge. They further argue that only by instituting managed socialization firms can truly succeed in leveraging global knowledge. Organizational blogs are very powerful tool for 'managed socialization'.

Williams and Jacobs (2004) postulate that blogs can generate knowledge from existing information by contextualising the information in a way that adds value to that information. Such knowledge can be shared with the use of the blogs and thus blogs are useful tools for organizational learning as well as knowledge transfer.

We believe that Stafford and Canary's (1991) taxonomy of relational maintenance strategies is relevant for study of the phenomenon of blogs as it provides a theoretical link between strategies that are found to be effective in context of interpersonal communications and the resulting favourable outcomes in public relations. Later work by Canary and Stafford's (1992) listed the five maintenance strategy factors as follows: 'positivity (interacting with partners in a cheerful, uncritical manner); openness (directly discussing the nature of the relationship and disclosing one's desires for the relationship); assurances (communicating one's desire to continue with the relationship); social networks (relying on common affiliations and relations); and sharing tasks (performing one's responsibilities)'.

In another significant contribution, Hon \& Grunig (1999) built on the works of Huang (1997) and Canary \& Stafford (1992) in the context of relationship between organization and the public. They adapted important terms from the study of interpersonal relationships which include definitions of 'trust, satisfaction, commitment, control mutuality, exchange relationships and communal relationships'. These terms have been conceptually as well as operationally well defined, and tested extensively as key variables in the study of organizationpublic relationships. Relationships between these variables and other constructs of central concern to public relations are thought to be of importance for empirical research for studying the success of the blogs. 
Apart from the above, Du and Wagner (2006) have proposed a techno-social success model for weblogs. This model postulates that the ability of a weblog to provide value for its users and readers at the content, the technology, and the social levels will determine its success. Several metrics are generally used for measuring the success of a blog (Stephens, 2013). The first metric is the number of blog entries which provides an indication of the frequency of updates. Another metric is the end user comments which provide us a degree of interaction between the blog author and the reader. The third metric is the number of visits on the blog itself. Finally, the rating of the end user by number of likes or rating of the blog too is another measure of success.

Microsoft's internal blogging community was studied by Efimova \& Grudin (2007) to understand how, where, and why employees blog. They concluded that "for an employer, this can result in accelerated information flow, increased productivity, improved reputation and customer engagement, but also in greater dependence on personalities, less control over the corporate face to the outside world and possible challenges to hierarchy". Within the organization, they found that there was disagreement on the topics and contents appropriate for blogging. They observed that while too restrictive scope of the organizational blog may stifle the purpose for which the blog is set up, employees have to be responsible enough to see that their comments do not adversely affect the team relationships in the organization.

Jina et al. (2007) explored employees' use of internal corporate blogs in large multi-national corporations such as IBM and found that the blogs are an important enabling tool for providing easy access to tacit knowledge that is embedded with experts. The blogs contribute towards developing collaboration across a broad range of such experts with communities in the enterprise.

Moderation and censorship are some of the tools used by organizations to control the nature of comments on organizational blogs (Wright, 2006). Some organizations lay down a detailed policy for guiding employee's online behaviour and provide links for reporting obnoxious comments to the administrators. Edward (2002) has described the possible roles of administrators in such situations.

\section{IDENTIFICATION AND SELECTION OF FRAMEWORK FOR THE STUDY Identification of frameworks}

From the literature review it is evident that there are not many frameworks to understand the organizational factors that are likely to have an impact on the level of adoption and use of blogs in the organizations for the purpose of organizational learning. We were able to identify only two such framework in the literature referred in the previous section, namely, Canary and Stafford's (1992) five maintenance strategy factors and Hon \& Grunig's (1999) six factors of interpersonal relationships in the context of organization-public relationships which may be for identification a set of factors which can have an impact on the efficacy of blogs as a tool of managed socialization in organizations. A comparison of these two frameworks presented in Table 1 will enable to appreciate the similarities and differences in the factors which are likely to affect the success of the organizational blogs.

The frameworks above suggest that the blogs which support these factors are likely to lead to greater social exchange of information. This is critically important in the organizational setting because organizational structures create politics and barriers to communications. Therefore the social media, in the form of organizational blogs, provides opportunities for the employees 
to move beyond the barriers imposed by such organizational structure by creating the sense of a one-on-one communication.

Table 1: Frameworks of Organizational Factors

\begin{tabular}{|l|l|}
\hline \multicolumn{1}{|c|}{$\begin{array}{c}\text { Canary \& Stafford's Maintenance Strategy } \\
\text { Factors }\end{array}$} & Hon \& Grunig's Factors of Interpersonal Relationships \\
\hline $\begin{array}{l}\text { Positivity of cheerful interaction with partners } \\
\text { in a uncritical manner }\end{array}$ & Trust of the other party \\
\hline $\begin{array}{l}\text { Openness of the relationship by clearly spelling } \\
\text { out one's desires for the relationship }\end{array}$ & $\begin{array}{l}\text { Satisfaction due to favourable disposition toward the } \\
\text { other leading to reinforcing of relationship }\end{array}$ \\
\hline $\begin{array}{l}\text { Assurances by way of articulating one's desire } \\
\text { to continue with the relationship }\end{array}$ & $\begin{array}{l}\text { Commitment built by the belief that the efforts } \\
\text { required to maintain and promote the relationship are } \\
\text { worthwhile. }\end{array}$ \\
\hline $\begin{array}{l}\text { Social networks by depending upon common } \\
\text { affiliations and relations }\end{array}$ & $\begin{array}{l}\text { Control mutuality which implies that parties agree on } \\
\text { the extent of the power that they have to influence } \\
\text { one another }\end{array}$ \\
\hline $\begin{array}{l}\text { Sharing tasks by performing one's } \\
\text { responsibilities }\end{array}$ & $\begin{array}{l}\text { Exchange relationships in which benefits are } \\
\text { exchanged among the parties for mutual benefits in } \\
\text { return for exchanges that have taken place earlier or } \\
\text { are likely to occur in future }\end{array}$ \\
\hline \multicolumn{2}{|c|}{$\begin{array}{l}\text { Communal relationship where benefits are exchanged } \\
\text { only for welfare of the other party. }\end{array}$} \\
\hline
\end{tabular}

\section{Selection of Framework for the Study}

The framework suggested by Hon and Grunig is focussed at organizational level in public relations context whereas the framework suggested by Canary \& Stafford is set up at individual level of relationship building in the context of marriage. Although both the frameworks include the constructs that affect interpersonal relationship- one for public relationships and the other for personal relationships, it is felt that the framework of Hon \& Grunig is more suited to the research question that is being discussed in this study as it is more closely linked to organizational settings and provides a more holistic view of managed socialization by including the construct of control mutuality which is essential for success of knowledge sharing through managed socialization. Therefore we select the framework suggested by Hon and Grunig for the present study.

\section{Propositions for the Study}

Based on the selected framework of Hon \& Grunig, we put forth the following propositions that will be tested and validated in this study:

- P1: Presence of trust among the stakeholders of an organizational blog will lead to its efficacy.

- P2: Presence of satisfaction among the stakeholders of an organizational blog will lead to its efficacy.

- P3: Presence of commitment among the stakeholders of an organizational blog will lead to its efficacy.

- P4: Presence of control mutuality among the stakeholders of an organizational blog will lead to its efficacy.

- P5: Absence of exchange relationships among the stakeholders of an organizational blog will lead to its efficacy.

- P6: Presence of communal relationships among the stakeholders of an organizational blog will lead to its efficacy. 
These propositions are depicted in Figure 1

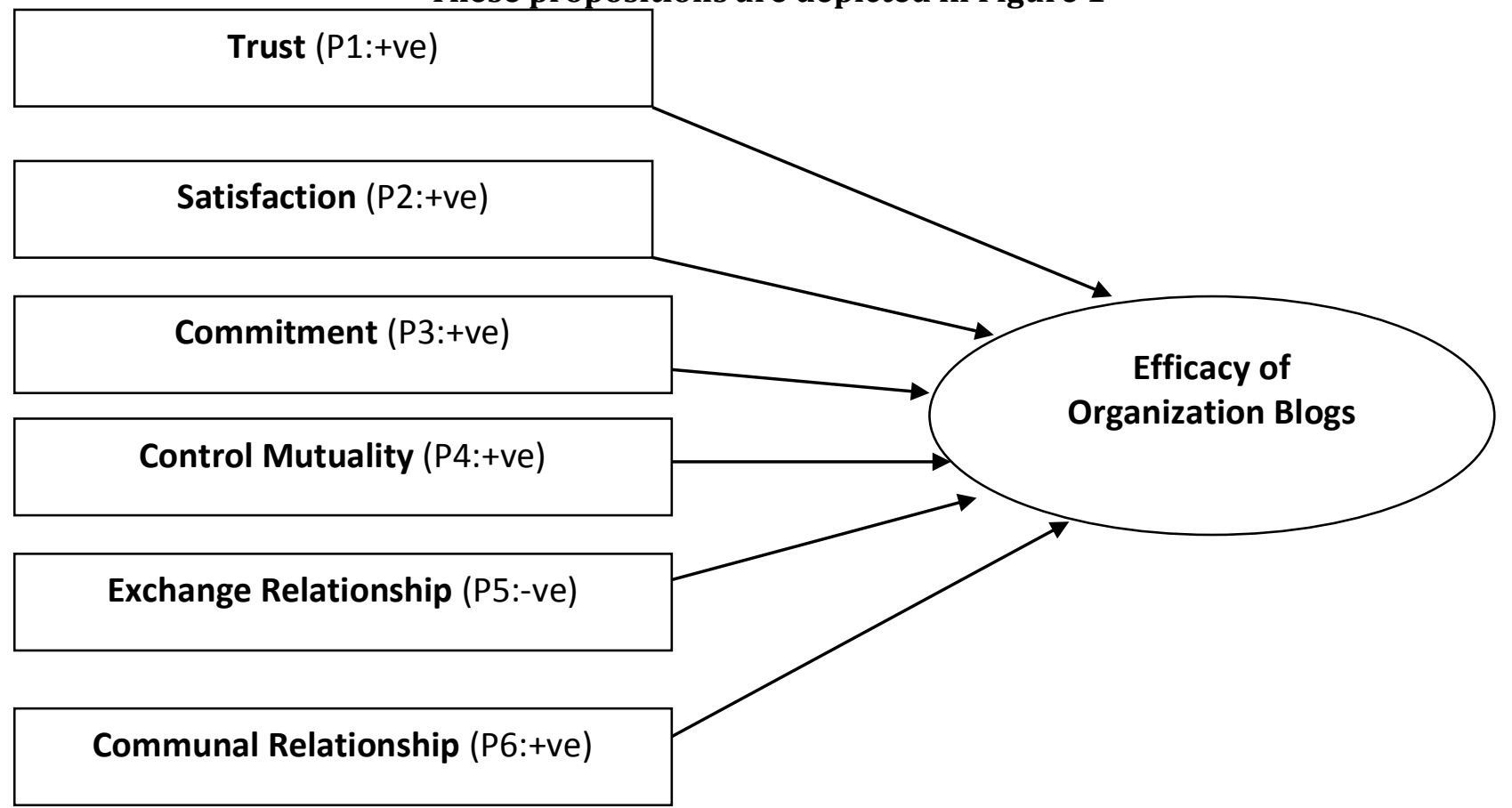

Figure 1: Model depicting the propositions of the study

\section{VALIDATION OF PROPOSITION}

In order to validate the propositions, we studied a leading service provider of India in the field of communication. Two sets of data were used: one when the discussion forum was being used by employees mainly for knowledge sharing and second just before it was decided to be closed by the management.

The organization under study has wide geographic dispersion with high knowledge diversity among the employees across locations. The employees positioned at nodal centres acquire latest tacit knowledge of new technologies and processes by way of their continuous interaction with peers and vendors while the employees at other locations depend on employees at nodal centres for dissemination of information. This situation adversely impacts business prospects as well as employee morale. While non-uniform distribution of knowledge among the employees results in customer dissatisfaction leading to loss of business, it also results in a feeling of inadequacy among the employees.

The company introduced discussion board on its intranet to address this critical issue of knowledge sharing. The discussion board was envisaged to enable knowledge sharing of the common issues being faced by its employees in its pan-India operations. Access to discussion board was restricted to the employees of the company with a username and password for accessing intranet. It was very successful in its objectives as it allowed the employees to post their queries related to operational problems. It facilitated diffusion of tacit expertise of few employees across the organization. It was used as a valuable tool for implementing managed socialization which denotes a managed process with the support of knowledge activists to induce socialization within organization by creating platforms that promote interaction and collaboration for circulating and assimilating tacit knowledge. In this way, it helped in building a sense of belongingness and sharing among its employees.

However, a series of events in the organization led to abuse of this successful technology tool which ultimately led to its closure. A bulk of middle and senior management employees were working in this company on deputation from another government organization. As a result of 
some judicial intervention, they were ordered to be repatriated to their parent organization. In order to ensure continuity of operations, the management decided to relieve them in phases rather than in one go. This hesitation on part of management irked the permanent employees of the organization as they wanted complete repatriation.

This tussle between permanent employees and employees on deputation reflected in posting on the discussion board which was available as a means for sharing views across the organization. The bickering on this organizational platform resulted in decrease in trust, reduced satisfaction and doubts about the commitment of employees on both sides. We capture these changes in organizational environment based on discussions with several officers and employees of the company in Table 2.

Table 2: Comparison of Factors affecting efficacy of blogs in 2009 and 2011

\begin{tabular}{|l|l|l|}
\hline \multicolumn{1}{|c|}{ Hon \& Grunig's Factors } & \multicolumn{1}{|c|}{2009} & \multicolumn{1}{c|}{2011} \\
\hline Trust & $\begin{array}{l}\text { High due to assurance } \\
\text { resulting from solution of } \\
\text { problems }\end{array}$ & $\begin{array}{l}\text { Low due to mutual feeling of } \\
\text { betrayal among the two } \\
\text { employee groups }\end{array}$ \\
\hline Satisfaction & $\begin{array}{l}\text { High as both groups of } \\
\text { employees perceived the } \\
\text { other as contributing to the } \\
\text { company }\end{array}$ & $\begin{array}{l}\text { Low as action of each group } \\
\text { were perceived to be harming } \\
\text { the company }\end{array}$ \\
\hline Commitment & $\begin{array}{l}\text { Moderate as each group did } \\
\text { not question the commitment } \\
\text { of the other }\end{array}$ & $\begin{array}{l}\text { Low as each group doubted } \\
\text { the commitment of the other }\end{array}$ \\
\hline Control mutuality & $\begin{array}{l}\text { High as hierarchy of control } \\
\text { was unambiguous }\end{array}$ & $\begin{array}{l}\text { Low as the officers group was } \\
\text { perceived to be hanging on } \\
\text { inspite of court orders }\end{array}$ \\
\hline Exchange relationships & $\begin{array}{l}\text { Low because relationship } \\
\text { between two groups was } \\
\text { based on hierarchy, not on } \\
\text { exchange of benefits }\end{array}$ & $\begin{array}{l}\text { High because the thread of } \\
\text { hierarchy was broken by the } \\
\text { court order for reliving the } \\
\text { officers }\end{array}$ \\
\hline Communal relationships & $\begin{array}{l}\text { High because of long-standing } \\
\text { relationship between two } \\
\text { groups }\end{array}$ & $\begin{array}{l}\text { Very low because each group } \\
\text { identified self-interest in } \\
\text { action of the other. }\end{array}$ \\
\hline
\end{tabular}

Based on perception of several employees and officers of the company as per their discussion with authors

\section{Data Analysis of posts on discussion forum}

We collected the contents of the posts for the period of 20 days just preceding closure of discussion forum in 2011 and compared it with a sample period of equal duration in 2009 to understand the difference in frequency and contents of the posts and the results are presented in Table 3.

Table 3: Comparison of count of threads and responses

\begin{tabular}{|l|c|c|c|c|}
\hline \multirow{2}{*}{ Item } & \multicolumn{2}{|c|}{ 3rd May-21st May 2009 } & \multicolumn{2}{c|}{ 10th Nov-29th Nov 2011 } \\
\cline { 2 - 5 } & Count & Average per day & Count & Average per day \\
\hline New threads & 106 & 6 & 145 & 8 \\
\hline Responses to threads & 475 & 25 & 792 & 42 \\
\hline Total & $\mathbf{5 8 1}$ & $\mathbf{3 1}$ & $\mathbf{9 3 7}$ & $\mathbf{5 0}$ \\
\hline
\end{tabular}

Source: Intranet discussion forum data obtained from the company

For the period 3rd May-21st May 2009, there were 581 entries out of which 106 were new threads initiated and 475 posts were in response to these threads which indicated that the 
forum was widely used by the employees with 31 posts per day on average. However, during the turbulence period in 2011, this increased by nearly $66 \%$ to average 50 posts per day.

Next, category-wise analysis of these threads entries was done to find out the topics which led to such drastic increase in number of posts in 2011. Comparison of topic-wise count of threads is shown in Table 5 below which shows that posts in Administration section increased from 26 to 98 and comprised $67.6 \%$ of total posts as compared to earlier $23.5 \%$ in 2010.

Table 4: Comparison of topic-wise count of threads on Discussion Board

\begin{tabular}{|l|c|c|c|c|}
\hline \multirow{2}{*}{ Category of comment } & \multicolumn{2}{|c|}{ 3rd May-21st May 2009 } & \multicolumn{2}{c|}{ 10th Nov-29th Nov 2011 } \\
\cline { 2 - 5 } & Count & \% of total & Count & \% of total \\
\hline Administration & 26 & $\mathbf{2 4 . 5}$ & 98 & $\mathbf{6 7 . 6}$ \\
\hline Basic Services & 4 & 3.8 & 1 & 0.7 \\
\hline Business Development & 3 & 2.8 & 6 & 4.1 \\
\hline Customer Service & 2 & 1.9 & 2 & 1.4 \\
\hline Finance & 7 & 6.6 & 6 & 4.1 \\
\hline Internet & 12 & 11.3 & 2 & 1.4 \\
\hline Marketing & 10 & 9.4 & 3 & 2.1 \\
\hline Mobile & 13 & 12.3 & 8 & 5.5 \\
\hline Technical Issues & 7 & 6.6 & 8 & 5.5 \\
\hline Miscellaneous & 22 & 20.8 & 11 & 7.6 \\
\hline \multicolumn{1}{r|}{ Total } & $\mathbf{1 0 6}$ & $\mathbf{1 0 0 . 0}$ & $\mathbf{1 4 5}$ & $\mathbf{1 0 0 . 0}$ \\
\hline
\end{tabular}

(Source: Intranet discussion forum data obtained from the company)

This increase in administration related posts was accompanied with significant decrease in posts related to Internet, marketing and mobile services which shows that the blog was not used as productive knowledge tool for important technical and business related discussions but more for issues arising out of the repatriation issue. Next, content analysis of the posts in these two periods was carried out to see whether the discussion forum was used as a means of flaming and polarized debates among the employees. Some of the contents during 2009 and 2011 are reproduced in Table 5 and Table 6 respectively to illustrate the tone of the discussions.

Table 5: Sample comments on discussion board in 2009

Whenever I try to open a site i am redirected to a webpage The webpage asks to enter username and password to continue. I have tried all the usernames and passwords but am not able to continue surfing. Please tell how this prob can be solved...thanx

Kindly guide me how to provide $20 \%$ rebate to existing multiplay customers.

Sir I got difficulties in login using Nokia E-71. Every time login window gets hided bellow the gif image window. It should be on top all the time. Moreover the viewing experience also is poor using mobile though it's having full HTML browser and it was similar to pc view earlier. Thanx.

After opening DB and selecting a discussion there should be a navigation for previous and next discussion. This will help to one who wants to participate in the discussion in sequence. Also we can give numbering to discussions and navigation for directly accessing the discussion by entering the numbering.

When I go for update profile I am getting the following error message "Warning: mysq_select_db (): supplied argument is not a valid MySQL. It was replied by Reddy on 7th May that this problem was solved. But still exists. Mr.Reddy pl look in this!

The new website has problems when viewed with Google Chrome.. 
Table 6: Sample comments on discussion board in 2011

\begin{tabular}{l} 
It is the need of the hour to throw out all ROTTEN EGGS early to make our HOUSE clean and worthy. \\
\hline They are dreaming of becoming DGM, GM directly. Let us wait till they wake up. \\
$\begin{array}{l}\text { They are not worried of job, they are worried about their salary and pension which they will get even they } \\
\text { fail to get the work. }\end{array}$ \\
$\begin{array}{l}\text { They are inefficient and direction less who contribute minimum (though some officers in this lot too are } \\
\text { reasonably good but not the majority) totally confused lot. }\end{array}$ \\
$\begin{array}{l}\text { Unending hatred against deputed officers seems to be the order of the day. Better it should end. } \\
\text { It is not possible to get freedom as board is dominated by officers on deputation. } \\
\text { And there should not be any dual standards in respect of protection of salary, pension and seniority } \\
\text { between two groups. }\end{array}$
\end{tabular}

The table illustrates the discussion forum's misuse by some section of employees to spread distrust and hatred in the organization and points towards potential pitfalls of the medium.

By looking at the data in Tables 2 to 6 it is seen that the propositions in section 3 are supported. The efficacy of discussion forum went down as the organization environment deteriorated in 2011.

\section{CONCLUSIONS, LIMITATIONS AND FUTURE RESEARCH}

We started the study with the objective of examining the factors which may lead to efficacy of the organizational blog which is an exciting tool of knowledge sharing and collaboration, especially in a large organization where the knowledge is geographically dispersed. We identified from literature that the Hon \& Grunig's framework for interpersonal relationships factors may be appropriate for this purpose. The propositions were then tested using a case study of an Indian company which had to resort to the extreme step of closing down its online discussion forum due to misuse of the forum by section of employees.

The results demonstrate that our propositions regarding impact of factors identified in Hon and Grunig framework on efficacy of organizational blogs hold valid. It can be inferred that once the atmosphere of the organization is vitiated, this forum stands to lose its appeal and may, in fact, lead to accelerated deterioration of the relations among the employees. Therefore the organizations have to be very careful in handling this double edged sword.

The issues raised in the case study can perhaps be resolved using Wright's (2006) concept of use of moderators for democratic participation in online discussion forum. The use of a moderator can help to improve the quality of the discussion although not much has been established about the extent of their exact role. Should they work towards evolving consensus or simply act as a censor by deleting controversial posts? Edwards (2002) has outlined three primary functions of a moderator. First is that of defining the boundaries of discussion by displaying policy guidelines for the users at the time of login. This method might have worked perfectly well in the case study discussed above- the moderator could have clearly stated that the forum is only for technical and knowledge sharing discussions and other non-related posts will be straightaway deleted. Further, second function of the moderators is to enrich the discussion by providing information and attracting participants while the third function is related to housekeeping functions such as keeping the discussion board up-to date, providing schedule for discussion etc. 
Operationally, a link for reporting acidic comments can be provided on the organizational blog. It is to be ensured that the reported content is seen and acted upon by the administrator in a fair and transparent manner for gaining trust of all users of the organizational blogs.

The limitation of the study is that it has evaluated factors contained in Hon and Grunig framework only. It is possible that some other factors may be able to explain the phenomenon more comprehensively. Further, our conclusions are based on single case study using qualitative research. More robust result can perhaps be obtained by using quantitative studies using scales of measurement on each factor on multiple organizations. It would also be useful to study the actual participants of the blogs in order to ensure that these are not some disgruntled employees who are using blogs for negative posts.

In spite of the aforementioned limitations, the paper contributes to academia as well as to the practitioners. From the academic point of view, it is an interesting research which validates the theoretical frameworks used in the study to identify the determinants of this powerful knowledge sharing tool which is widely used in recent times by many organizations with the belief that it essentially produces good knowledge sharing results.

From a practising manager's perspective, the study enables them to prepare the organization for taking preventive action for possible misuse of this knowledge sharing tool and avoid the possible pitfalls by suggesting the strategy of deployment of moderators to improving the efficacy of this powerful tool.

\section{Bibliography}

Baoill, A. (2004). Conceptualizing the weblog: Understanding what it is in order to imagine what it can be. Interfacings: Journal of Contemporary Media Studies, 5(2), 1-8.

Baxter, G. J., \& Connolly, T. M. (2013). The "state of art" of organisational blogging. Learning Organization, the, 20(2), 104-117.

Bishop, T. Microsoft Fires Worker over Weblog. Seattle Post-Intelligencer, 30 October 2003

Canary, D. J., \& Stafford, L. (1992). Relational maintenance strategies and equity in marriage. Communication Monographs, 59(3), 243-67.

Carlin, S., Lee, J., Lemons, D., O'Dell, C., \& Swift, G. (2008). The Role of Evolving Technologies: Accelerating Collaboration and Knowledge Transfer: APQC. Cone, E. Rise of the Blog. CIO Insight, 5 April 2005

Du, H. S., \& Wagner, C. (2006). Weblog success: Exploring the role of technology. International Journal of HumanComputer Studies, 64(9), 789-798.

Edwards, A. 2002. The Moderator as an Emerging Democratic Intermediary: The Role of the Moderator in Internet Discussions about Public Issues. Information Polity 7(1): 3-20.

Efimova, L. \& Grudin, J. (2007). Crossing boundaries: A case study of employee blogging.

Proceedings of the Fortieth Hawaii International Conference on System Sciences (HICSS-40). Los Alamitos: IEEE Press.

H. Jina, J. Lauretta, E. Thomas, A. K. Wendy, K. E. B. Rachel, and C. T. John, "BlogCentral: the role of internal blogs at work," in CHI '07 extended abstracts on Human factors in computing systems San Jose, CA, USA: ACM, 2007.

Hasan, H., \& Pfaff, C. (2006). The Wiki: a tool to support the activities of the knowledge worker. Paper presented at the Proceedings at the Transformational Tools for 21st Century

Hon, L. C., \& Grunig, J. (1999). Guidelines for measuring relationships in public relations. Gainesville, FL: The Institute for Public Relations. Retrieved January 26, 2006, from

$\backslash$ http://www.instituteforpr.com/pdf/1999_guide_measure_relationships.pdf 
Huang, Y. H [1997]. Public Relations Strategies, Relational Outcomes, and Conflict Management Strategies, Unpublished Doctoral Dissertation, University of Maryland, College Park.

Kaiser, S., Müller-Seitz, G., Lopes, M. P., \& e Cunha, M. P. (2007). Weblog-technology as a trigger to elicit passion for knowledge. Organization, 14(3), 391-412.

Kearns, I., J. Bend, and B. Stern. 2002. E-participation in Local Government. London: Institute for Public Policy Research.

Kelleher, T. (2009). Conversational voice, communicated commitment, and public relations outcomes in interactive online communication. Journal of communication, 59(1), 172-188.

Kelleher, T., \& Miller, B. M. (2006). Organizational blogs and the human voice: Relational strategies and relational outcomes. Journal of Computer-Mediated Communication, 11(2), 395-414.

Lee, H. H., Park, S. R., \& Hwang, T. (2008). Corporate-level blogs of the Fortune 500 companies: an empirical investigation of content and design. International Journal of Information Technology and Management, 7(2), 134148.

McAfee, A. P. (2009). Shattering the myths about Enterprise 2.0. IT Management Select, 15(4), 28.

Moitra, D., \& Kumar, K. (2007). Managed socialization: how smart companies leverage global knowledge. Knowledge and Process Management, 14(3), 148-157.

Ojala, M. (2004), "Weaving weblogs into knowledge sharing and dissemination. Nord I\&D, knowledge and change", Proceedings of the 12th Nordic Conference on Information and Documentation, 1-3 September 2004, Aalborg. Nord I\&D Knowledge and Change, available at: www2.db.dk/NIOD/ojala.pdf (accessed 30 September 2008).

Roll, M. (2004), “Distributed KM - improving knowledge workers' productivity and organizational knowledge sharing with web log-based personal publishing”, paper presented at BlogTalk 2.0, "The European Conference on Weblogs", Vienna, July 5-6.

Silva, L., Mousavidin, E. and Goel, L. (2006), “Weblogging: implementing communities of practice”, in Trauth, E., Howcroft, D., Butler, T., Fitzgerald, B. and DeGross, J. (Eds), IFIP International Federation for Information Processing, Vol. 208, Social Inclusion: Societal and Organizational Implications for Information Systems, Springer, Boston, MA, pp. 295-316.

Stafford, D. J., \& Canary, L. (1991).Maintenance strategies and romantic relationship type, gender and relational characteristics. Journal of Social and Personal Relationships, 8(2), 217-42.

Stata, R. (1989), “Organizational learning - the key to management innovation”, Sloan Management Review, Vol. 30 No. 3, pp. 63-74.

Stephens, R. T. (2013, April). Success in a large scale corporate blogging environment. In Southeastcon, 2013 Proceedings of IEEE (pp. 1-6). IEEE.

Wattal, S., Racherla, P., \& Mandviwalla, M. (2009, January). Employee adoption of corporate blogs: A quantitative analysis. In System Sciences, 2009. HICSS'09. 42nd Hawaii International Conference on (pp. 1-10). IEEE.

Website http://www.adelaide.edu.au/myuni/staff/resources/tutorials/content/Differences between _Discussion_Boards_Blogs_and_Wikis.html accessed on 24th Feb 2014.

Website http://www.bsnl.co.in/opencms/bsnl/BSNL/about_us/finance/finance.html accessed on 15 th Feb 2014.

Wenger, E. (1991), “Communities of practice: where learning happens”, Benchmark, fall, pp. 1-6.

Williams, J. B., \& Jacobs, J. (2004). Exploring the use of blogs as learning spaces in the higher education sector. Australasian Journal of Educational Technology, 20(2), 232-247.

Wright, S. (2006). Government-run Online Discussion Fora: Moderation, Censorship and the Shadow of Control1. The British Journal of Politics \& International Relations, 8(4), 550-568.

Wright, S. (2009). The role of the moderator: problems and possibilities for government-run online discussion forums. Online deliberation: Design, research, and practice, 233-242 